\title{
Biodegradable nanocomposites based on PLA/PHBV blend reinforced with carbon nanotubes with potential for electrical and electromagnetic applications
}

\author{
A. P. B. Silva*, L. S. Montagna, F. R. Passador, M. C. Rezende, A. P. Lemes
}

Polymer and Biopolymer Technology Laboratory (TecPBio), Universidade Federal de São Paulo (UNIFESP), 330 Talim St, 12231-280 São José dos Campos, SP, Brazil

Received 8 April 2021; accepted in revised form 11 June 2021

\begin{abstract}
The production of poly(lactic acid) (PLA) biodegradable blends with other biopolymers, such as poly(3-hydroxybutyrate-co-3-hydroxyvalerate) (PHBV), and the introduction of carbon nanotubes (CNT) are promising solutions for electrical and electromagnetic application. PHBV has a great potential to improve the processing and toughness of PLA. The addition of CNT contributes to the electrical and electromagnetic properties of polymeric nanocomposites. PLA/PHBV blend (80/20) and PLA/PHBV blend-based nanocomposites with 0.5 and $1.0 \mathrm{wt} \%$ of CNT were produced. Morphology images showed the homogeneous dispersion of PHBV domains in PLA, and that CNTs are preferably dispersed in the PHBV phase. The CNT acted as a nucleating agent for the crystallization of PHBV and did not affect the thermal stability of the nanocomposites. CNT reduced the Izod impact strength; however, flexural properties were not affected. The addition of $1.0 \mathrm{wt} \%$ CNT resulted in better electrical properties $\left(2.79 \cdot 10^{-2} \mathrm{~S} / \mathrm{m}\right)$ and an excellent result as electromagnetic interference shielding material (attenuation of approximately $96.9 \%$ of the radiation in X-band). Biodegradable nanocomposite based on PLA/PHBV blend reinforced with $1.0 \mathrm{wt} \% \mathrm{CNT}$ presented interesting properties for possible applications in electronic device and military sectors.
\end{abstract}

Keywords: nanocomposites, biodegradable polymers, poly(lactic acid), poly(3-hydroxybutyrate-co-3-hydroxyvalerate), carbon nanotubes

\section{Introduction}

The life cycle of durable materials has declined over the decades due to the development of technologies that make such equipment obsolete in shorter periods. This is the case with consumer electronics, such as televisions, computers, and mobile phones, which have a shorter life cycle due to their replacement with superior models launched every year [1]. Thus, the use of biopolymers such as poly(lactic acid) (PLA) for the production of these durable items is desirable since the volume generated by the disposal of this electronic equipment is increasing and difficult to handle [2].

\footnotetext{
*Corresponding author, e-mail: anapaula.silva.sjc@hotmail.com C BME-PT
}

PLA is a biodegradable and biocompatible polyester being produced from renewable resources, like corn $[3,4]$. Due to these characteristics, the PLA had great prominence in the packaging sector because of its short life cycle [5-8]. Although demand has appeared first in the packaging sector, today, its use in durable structural parts and semi-structural parts has increased. It is estimated that the production of this biopolymer will increase further in the coming years $[2,7,9]$.

However, even with some properties similar to conventional thermoplastics $[7,10]$, PLA has low impact strength, toughness, and thermal resistance, 
making its application difficult $[2,8,10]$. In this way, the development of PLA blends with other biopolymers and PLA nanocomposites has been shown as alternative routes to improve these properties $[2,6$, 10-22].

Poly(3-hydroxybutyrate-co-3-hydroxyvalerate) (PHBV) is a polyester belonging to the polyhydroxyalkanoate (PHA) family. It is a straight-chain semicrystalline copolymer produced from biomass and also biodegradable, such as PLA [8, 23, 24]. Because of its characteristics, PHBV is one of the most studied biopolymers in the production of blends withPLA [10, 11, 16, 17, 25, 26].

In these works, the authors observed the immiscibility in all PLA/PHBV blend compositions and the homogeneous dispersion of the phase-in smaller proportion [11, 16, 17]. Gerard et al. [16] analyzed the mechanical properties of the PLA/PHBV blend with different blend ratios, and (90/10) and (80/20) blends showed high elongation at break of 50.7 and 204\%, respectively, while the PLA presented an elongation at break of $4.8 \%$. Similar results in the mechanical properties were obtained by Ma et al. [17], with the addition of 10, 20, and $30 \mathrm{wt} \%$ PHBV in the PLA/ PHBV blend. The authors obtained values of elongation at break of $4 \%$ for the neat PLA, and of $200 \%$ up to $260 \%$ for the PLA/PHBV blends with 10 to $30 \mathrm{wt} \%$ PHBV. The increase of the impact toughness for notched samples was from $2.5 \mathrm{~kJ} / \mathrm{m}^{2}$ (neat PLA) to $10 \mathrm{~kJ} / \mathrm{m}^{2}$ for PLA/PHBV blend with the addition of $30 \mathrm{wt} \%$ PHBV. And for the un-notched specimens, the increase was from 16 to $150 \mathrm{~kJ} / \mathrm{m}^{2}$ for the PLA/PHBV blend (80/20).

Among the nanoparticles used in biopolymers nanocomposites, the carbon nanotubes (CNT) have great prominence in several works [17-19, 27-40]. CNTs have excellent thermal (more than $3000 \mathrm{~W} /(\mathrm{m} \cdot \mathrm{K}$ ) at room temperature) [41], electrical (up to $10^{6}$ to $10^{7} \mathrm{~S} / \mathrm{m}$ ) [42], and structural properties (elasticity modulus in the TPa range and tensile strength up to $50 \mathrm{GPa})[43,44]$ that depend directly on their diameter and chirality. CNT are added to improve the mechanical, thermal, and electrical properties of the polymer matrix [42, 45-51].

Park et al. [19] observed an improvement in the mechanical and thermal properties of PLA/CNT nanocomposites. Low levels of CNT $(0.2 \mathrm{wt} \%)$ improved the tensile strength (from 52 to $67 \mathrm{MPa}$ ), the elastic modulus (from 1.70 to $1.88 \mathrm{GPa}$ ), and the thermal stability (Tonset from 360 to $385^{\circ} \mathrm{C}$ ) of PLA. Pinto et al. [18] produced PLA/CNT nanocomposites with 0.7 and $2.0 \mathrm{wt} \%$ of functionalized CNT with carboxyl groups (CNT-COOH). The nanocomposite with the addition of $0.7 \mathrm{wt} \% \mathrm{CNT}$ showed better mechanical properties, especially in tensile strength (increased of $21 \%$ ) and fracture toughness (increased of $22 \%$ ), in which it absorbed more energy before rupture compared to the neat polymer.

For the application of new materials in electronic devices, the study on electromagnetic shielding is necessary for the control of electromagnetic interference (EMI). Polymers with the addition of conductive particles and/or nanoparticles that allow such application (conductive polymer composites (CPC)) are gaining more attention since s are more lightweight, flexible, easy to process, and resistant to corrosion compared to metals $[9,52]$. EMI shielding in a material can be caused by three characteristics: absorption, reflection, and multiple-internal reflections of the electromagnetic wave [53]. Allied to the electromagnetic property is the electrical behavior of the nanocomposite because in order to have EMI shielding responses, the material must reach values of adequate electrical conductivity (between $10^{-3}$ and $1 \mathrm{~S} / \mathrm{m})$ [54].

The results of electrical properties presented by Mina et al. [36] for the PLA/CNT nanocomposites reveal a significant decrease in electrical resistivity of 13 orders of magnitude with the addition of $1.5 \mathrm{wt} \% \mathrm{CNT}$. These values show that the addition of CNT can improve the electrical conductivity of the nanocomposite. Another study showed a significant increase in the electrical conductivity with the addition of CNT in PLA nanocomposites [37]. Electrical conductivity of $10^{-17} \mathrm{~S} / \mathrm{cm}$ to PLA changed to $10^{-8} \mathrm{~S} / \mathrm{cm}$ with $1.5 \mathrm{wt} \% \mathrm{CNT}$ and $10^{-7} \mathrm{~S} / \mathrm{cm}$ with the addition of $2.0 \mathrm{wt} \%$ CNT. Urquijo et al. [15] studied the addition of CNT in the PLA/poly $(\varepsilon-$ caprolactone) blend. From the addition of $2 \mathrm{wt} \%$ $\mathrm{CNT}$, an increase by 7 orders of magnitude in the electrical conductivity and an increase of $12 \%$ in elastic modulus were observed with the addition of $5 \mathrm{wt} \% \mathrm{CNT}$. This result was justified by the preferential location of CNT in the PCL phase that it was observed in the transmission electron microscopy (TEM) micrographs.

The region between nanofillers and polymer matrix, called interphase, has a great influence on the final properties and must be considered in the prediction of mechanical and conductivity properties of CNT 
nanocomposites as appointed by Razavi et al. [47] and Zare et al. [55], as well, as the preferential location of the filler at one of the phases or at the blend interface. Blend morphology and immiscibility can also be improved with the location of the filler that can even act as a compatibilizer agent $[56,57]$. Usually, the location is on the component where the filler has a greater affinity or on the interface, where the energy level is lower when the components have little difference between them [57]. However, due to the kinetic factors of polymers and blends being generally immiscible, only the thermodynamic factor may not be sufficient to determine the preferred location of the nanoparticle in a blend. Therefore, other factors can influence the location, such as the degree of crystallinity of the phases, molar mass, and melt viscosity of the polymers, and the processing of the blend itself [57].

Thus, the introduction of CNT in PLA/PHBV blend proposed in this work shows an interesting and promising way to obtain the properties that allow PLA to be used in the production of durable electronic devices and that can be biodegradable after use. The composition of the PLA/PHBV blend $(80 / 20)$ was maintained in this work, as observed in the literature that this blend ratio showed better results in processing and improving PLA toughness $[16,17]$. And so, the effect of the addition of different contents of CNT on the morphology, mechanical, thermal, electrical, and electromagnetic properties of the PLA/PHBV blend was analyzed.

\section{Experimental}

\subsection{Materials}

PLA and PHBV used were purchased from NaturePlast (France), with trade names PLI005 and PHI002, respectively. The PLA has $\bar{M}_{\mathrm{w}}$ in the range of 80000 to $100000 \mathrm{~g} \cdot \mathrm{mol}^{-1}$, and the PHBV has $\bar{M}_{\mathrm{w}}$ in the range of 400000 to $500000 \mathrm{~g} \cdot \mathrm{mol}^{-1}$ with $2 \%$ of 3 hydroxyvalerate (HV) units, according to the supplier.

The multiwall carbon nanotubes (CNT) has supplied by Nanocyl ${ }^{\circledR}$ (Belgium) with the specification NC7000, with a diameter in the range of $9.5 \mathrm{~nm}$ and length in the range of $1.5 \mu \mathrm{m}$.

\subsection{Preparation of polymer blend nanocomposites}

PLA and PHBV pellets were previously oven-dried for $4 \mathrm{~h}$ at $70^{\circ} \mathrm{C}$. The blends and the nanocomposites were prepared in a high-speed mixer (DRAIS mixer) model MH50H (MH Equipamentos, Brazil), where $65 \mathrm{~g}$ of material were mixed with a rotating at $3000 \mathrm{rpm}$ for $1 \mathrm{~min}$. The high friction generation between the rotor and the polymers is responsible for the mixing, melting, and homogenization of the blend and nanocomposites. The mixture process is interrupted soon after the material fusion occurs, which is identified by a sudden fall of torque that probably occurs in a temperature range between $175-180^{\circ} \mathrm{C}$. After melting, the blends and nanocomposites were pressed in a hydropneumatic press model PR8HP (MH Equipamentos, Brazil) with a pressure of 5 bar for $3 \mathrm{~min}$ at $210^{\circ} \mathrm{C}$. The composition of PLA/PHBV blend $[\mathrm{w} / \mathrm{w}$ ] was $80 / 20$, and the blend ratio was maintained for the production of the nanocomposites with 0.5 and $1.0 \mathrm{wt} \%$ of CNT. The samples were denominated as PLA/PHBV, PLA/PHBV/0.5CNT, and PLA/PHBV/1.0CNT, respectively.

\subsection{Analytical characterization}

The cryogenically fractured surface morphologies of the blend and blend-based nanocomposites were analyzed by field emission gun scanning electron microscope (FEG-SEM) TESCAN model MIRA 3, operating at $5 \mathrm{kV}$. The samples were kept on $\mathrm{N}_{2}$ liquid for some minutes to reach thermal equilibrium and then fractured inside the $\mathrm{N}_{2}$ liquid. So, the samples were fixed on aluminum stubs and covered with a thin layer of gold.

The surface energy values of the solids can be obtained from the measurements of the contact angle analysis [58]. Applying the contact angle data in the Owens-Wendt method, the dispersive and polar components of the surface energy of a solid or liquid can be obtained, Equations (1) and (2) [59]:

$\gamma_{\mathrm{s}}=\gamma_{\mathrm{s}}^{\mathrm{d}}+\gamma_{\mathrm{s}}^{\mathrm{p}}$

$\gamma_{1}(1+\cos \theta)=2\left(\gamma_{s}^{\mathrm{d}} \gamma_{1}^{\mathrm{d}}\right)^{1 / 2}+2\left(\gamma_{\mathrm{s}}^{\mathrm{p}} \gamma_{1}^{\mathrm{p}}\right)^{1 / 2}$

where $\theta$ is the contact angle, $\gamma$ is the surface energy, the subscripts ' $l$ ' and ' $s$ ' indicate liquid and solid, respectively, while superscripts ' $p$ ' and ' $d$ ' indicate the polar and dispersive components, respectively. To obtain the surface energy values of the measured solid, it is necessary to carry out the analysis of contact angle with a polar and a non-polar liquid, applying the parameters $\gamma_{1}^{\mathrm{d}}$ and $\gamma_{1}^{\mathrm{p}}$ of both liquids in Equations (2) and (3). The literature values of surface energy of these liquids are $\gamma^{\mathrm{p}}=50.7 \mathrm{mN} / \mathrm{m}$ and 
$\gamma^{\mathrm{d}}=22.1 \mathrm{mN} / \mathrm{m}$ for $\mathrm{H}_{2} \mathrm{O}$, and $\gamma^{\mathrm{p}}=6.7 \mathrm{mN} / \mathrm{m}$ and $\gamma^{\mathrm{d}}=44.1 \mathrm{mN} / \mathrm{m}$ for $\mathrm{CH}_{2} \mathrm{I}_{2}[58,60]$.

The surfaces of the polymers were submitted to measurements of contact angle using a KRÜSS Goniometer mod. FM40. The wetting liquids were distilled water $\left(\mathrm{H}_{2} \mathrm{O}\right)$ and diiodomethane $\left(\mathrm{CH}_{2} \mathrm{I}_{2}\right)$ with the sessile drop method $\left(1.0 \mu 1,25^{\circ} \mathrm{C}\right)$. Three measurements were made for each sample, and the average was calculated. Two values from the literature were used for CNT surface energy [61, 62].

This way, the interfacial energy between two components can be calculated using surface energy and its parameters in the harmonic-mean Equation (3) and geometric-mean Equation (4) [58]:

$$
\begin{aligned}
& \gamma_{12}=\gamma_{1}+\gamma_{2}-4\left[\frac{\gamma_{1}^{\mathrm{d}} \gamma_{2}^{\mathrm{d}}}{\gamma_{1}^{\mathrm{d}}+\gamma_{2}^{\mathrm{d}}}+\frac{\gamma_{1}^{\mathrm{p}} \gamma_{2}^{\mathrm{p}}}{\gamma_{1}^{\mathrm{p}}+\gamma_{2}^{\mathrm{p}}}\right] \\
& \gamma_{12}=\gamma_{1}+\gamma_{2}-2\left[\left(\gamma_{1}^{\mathrm{d}} \gamma_{2}^{\mathrm{d}}\right)^{1 / 2}+\left(\gamma_{1}^{\mathrm{p}} \gamma_{2}^{\mathrm{p}}\right)^{1 / 2}\right]
\end{aligned}
$$

where $\gamma_{12}$ is interfacial energy between components 1 and $2, \gamma_{1}$ and $\gamma_{2}$ are the surface energies of components, $\gamma_{1}^{\mathrm{d}}$ and $\gamma_{2}^{\mathrm{d}}$ are the dispersive surface energies and $\gamma_{1}^{\mathrm{p}}$ and $\gamma_{2}^{\mathrm{p}}$ are the polar surface energies of the components in the blend nanocomposites.

To deduce the location of the third component in a blend using the wetting coefficient $\left(\omega_{\mathrm{a}}\right)$ Sumita et al. [63] elaborated the following Equation (5):

$\omega_{\mathrm{a}}=\frac{\gamma_{\text {PolymerB-filler }}-\gamma_{\text {PolymerA-filler }}}{\gamma_{\text {PolymerA }}-\text { PolymerB }}$

where $\gamma_{\text {PolymerB-filler, }} \gamma_{\text {PolymerA-filler, and }} \gamma_{\text {PolymerA-PolymerB }}$ are the interfacial energies between polymer B and filler, between polymer A and filler, between polymer A and B, respectively. Thus, the value of the wetting coefficient obtained predicts the distribution of the filler in the blend. If $\omega_{a}>1$, the filler is preferably in polymer $\mathrm{A}$; if $\omega_{\mathrm{a}}<-1$, the filler is in polymer $\mathrm{B}$; and if the value of $\omega_{\mathrm{a}}$ is between -1 and 1 , the filler is preferably in the interface of the polymers of the blend.

The miscibility of the polymers in the blend can also be calculated using the surface energy values of the polymers and the interfacial energy using the spreading coefficient, $\lambda^{12}$ (Equation (6)) [58]:

$$
\lambda_{12}=\gamma_{2}-\gamma_{1}-\gamma_{12}
$$

Differential scanning calorimetry (DSC) analyses of the samples were performed using TA Instruments
Q2000 equipment under nitrogen atmosphere. The samples $(8 \mathrm{mg})$ were placed into aluminum pans, heated at a rate of $10^{\circ} \mathrm{C} \cdot \mathrm{min}^{-1}$ until $200^{\circ} \mathrm{C}$, and kept at this temperature for $1 \mathrm{~min}$. Subsequently, the samples were cooled at a rate of $10^{\circ} \mathrm{C} \cdot \mathrm{min}^{-1}$ until $-50{ }^{\circ} \mathrm{C}$, kept at this temperature for $1 \mathrm{~min}$, and heated again to $200^{\circ} \mathrm{C}$. Therefore, the melting point $\left(T_{\mathrm{m}}\right)$, the crystallization temperature $\left(T_{\mathrm{c}}\right)$, the glass transition temperature $\left(T_{\mathrm{g}}\right)$, and the melting enthalpy $\left(\Delta H_{\mathrm{m}}\right)$ were obtained.

The thermogravimetric analysis (TGA) was performed using a TG $209 \mathrm{~F} 1$ Iris $^{\circledR}$ equipment (Netzsch). The samples $(12 \mathrm{mg})$ were heated at a rate of $20^{\circ} \mathrm{C} \cdot \mathrm{min}^{-1}$ from room temperature to $800^{\circ} \mathrm{C}$, under a nitrogen atmosphere.

The impact test was carried out according to ASTM D256-10 [64]. Impact tests were performed on CEAST/Instron Izod impact testing machine (model 9050 ) with a $2.75 \mathrm{~J}$ hammer. Five test samples of each composition were notched using a manual notched machine (CEAST/Instron).

The flexural test was done according to ASTM D790-10 [65] using a universal testing machine Instron (model 4301), with a load cell of $5 \mathrm{kN}$, at a crosshead speed of $2 \mathrm{~mm} \cdot \mathrm{min}^{-1}$. Five samples were used for each composition. Results were analyzed using one-way analysis of variance (ANOVA) on Microsoft Excel (Microsoft Office Professional Plus 2010).

The electrical conductivity values were obtained by impedance spectroscopy and measuring the electrical resistivity for alternating current. To form an electrical contact, producing a metal-nanocomposite-metal structure, a thin layer of gold/palladium alloy was deposited using a high vacuum coating system (MED020 Bal-tec) on both sides of the samples. The values were calculated using Equation (7):

$\sigma=\frac{1}{\rho}$

where $\sigma$ is the electrical conductivity and $\rho$ is the resistivity. The resistivity values were obtained from the relation between the impedance values and the electrical contact area dimensions of the samples, see Equation (8):

$\rho=\frac{Z \cdot A}{l}$

where $Z$ is the impedance, $A$ is the area, and $l$ is the thickness of the samples. The impedance was 
measured in an impedance analyzer, Solartron SI 1260 (Impedance/gain-phase analyzer), at room temperature at a frequency of $10 \mathrm{~Hz}$ and voltage amplitude of $0.5 \mathrm{~V}$.

Reflectivity measurements of radiation incident on the material were used for electromagnetic characterization of the blend and nanocomposites. It was performed by a waveguide technique in the frequency range of 8.2 to $12.4 \mathrm{GHz}$ (X-band) of the electromagnetic spectrum. Measurements were obtained by using a waveguide coupled to a Microwave Network Analyzer by Agilent Technologies (PNA-L N5230C model) with four ports and frequency range $300 \mathrm{kHz}$ to $20 \mathrm{GHz}$. The reference material used in the reflectivity measurements of the samples was an aluminum plate, which is $100 \%$ reflector or $0 \%$ attenuation. The equipment was calibrated at $50 \Omega$. All reflectivity measurements were done at room temperature, and the samples were prepared to dimensions $9.98 \mathrm{~mm} \times 22.80 \mathrm{~mm} \times 3.2 \mathrm{~mm}$.

\section{Results and discussion}

\subsection{Morphological characteristics: FEG-SEM}

Figure 1 presents the FEG-SEM micrographs of the cryogenically fractured surface of PLA/PHBV blend. The morphology of the PLA/PHBV blend is characteristic of an immiscible blend, since in the micrograph obtained in the FEG-SEM the PHBV domains, phase in lower concentration, dispersed in the PLA matrix are observed. The spherical domains of the PHBV are well dispersed in the matrix; however,

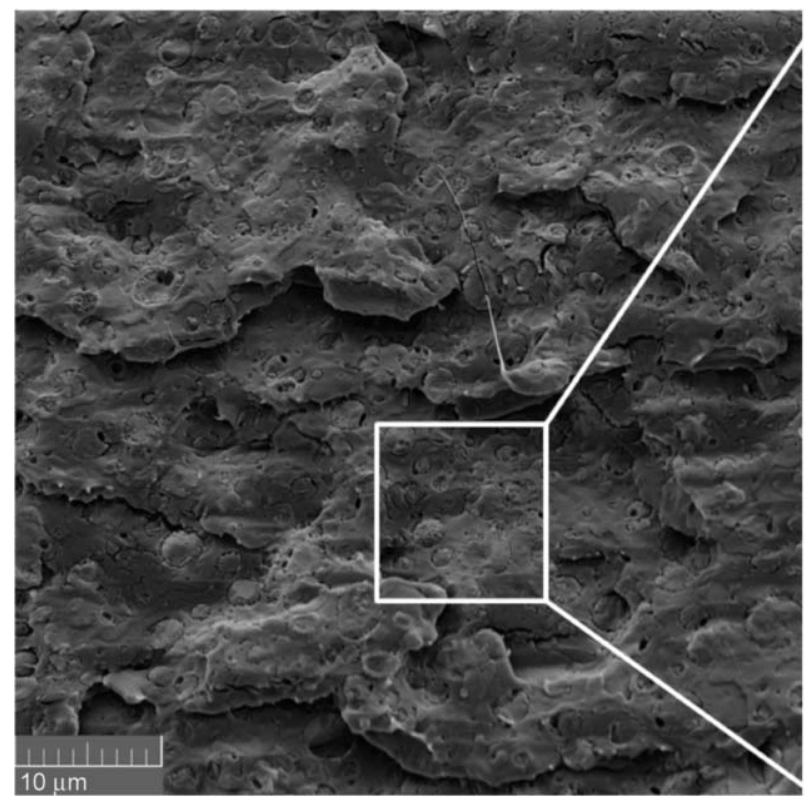

a) there are apparently and irregularities and voids between the phases (indicated in Figure $1 \mathrm{~b}$ by the white arrows) due to the blend immiscibility and a not so efficient mixing process. This morphology for PLA/ PHBV blends also were observed in the works of Ma et al. [17], and Gerard et al. [16] for PLA/PHBV blends with different blend ratios (80/20 and 75/25). The interface between both domains can be observed in greater detail in the magnification of the selected region of the micrograph (Figure $1 b$ ).

The PHBV domains are more defined in the PLA/ PHBV blend (Figure 1) and the PLA/PHBV/0.5CNT blend nanocomposite (Figure 2a, 2b) than in the PLA/PHBV/1.0CNT blend nanocomposite (Figure $2 c, 2 d)$. This result may have occurred due to the increased CNT concentration in the nanocomposite of the blends, resulting in a rougher fracture surface. The increase of the CNT content in the nanocomposite caused an increase in the roughness of the fracture surface.

In the micrograph of PLA/PHBV/0.5CNT (Figure 2a, 2b) and PLA/PHBV/1.0CNT (Figure 2c, 2d), it is noted that the CNT (indicated in the figure by withe arrows) are preferably located in the PHBV phase. Once CNT agglomerates were observed in the PHBV domains, there is an increase in the roughness of the fracture surface of the blend-based nanocomposites with the concentration of CNT. In the PLA/ PHBV/1.0CNT nanocomposite (Figure 2c, 2d), the CNTs are exposed in the fracture surface, and the presence of voids in the interface PHBV-CNT is

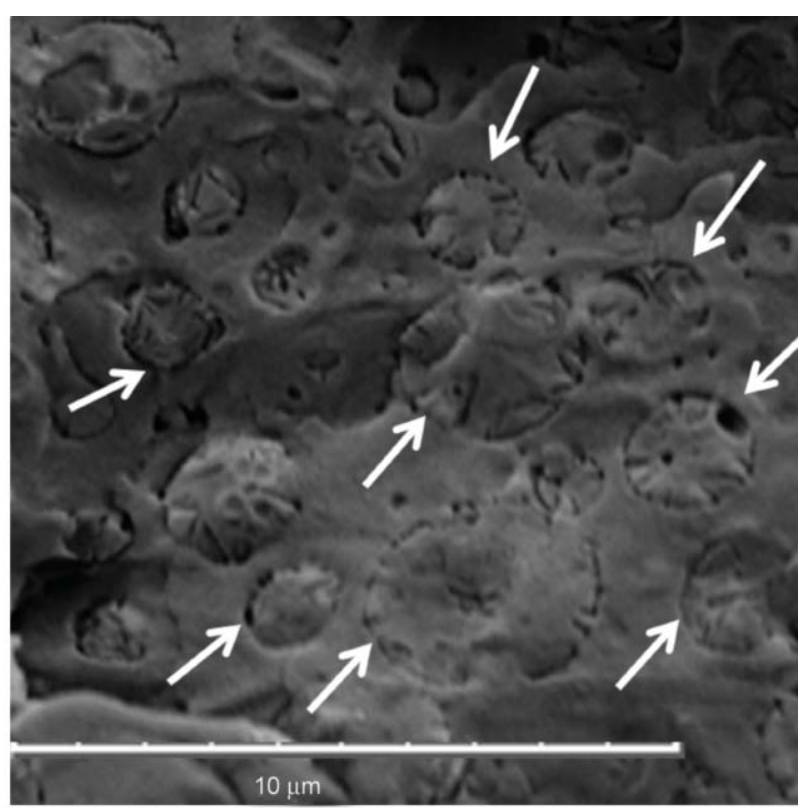

b)

Figure 1. (a) FEG-SEM micrographs of the PLA/PHBV blend; (b) magnification region of the micrograph. 


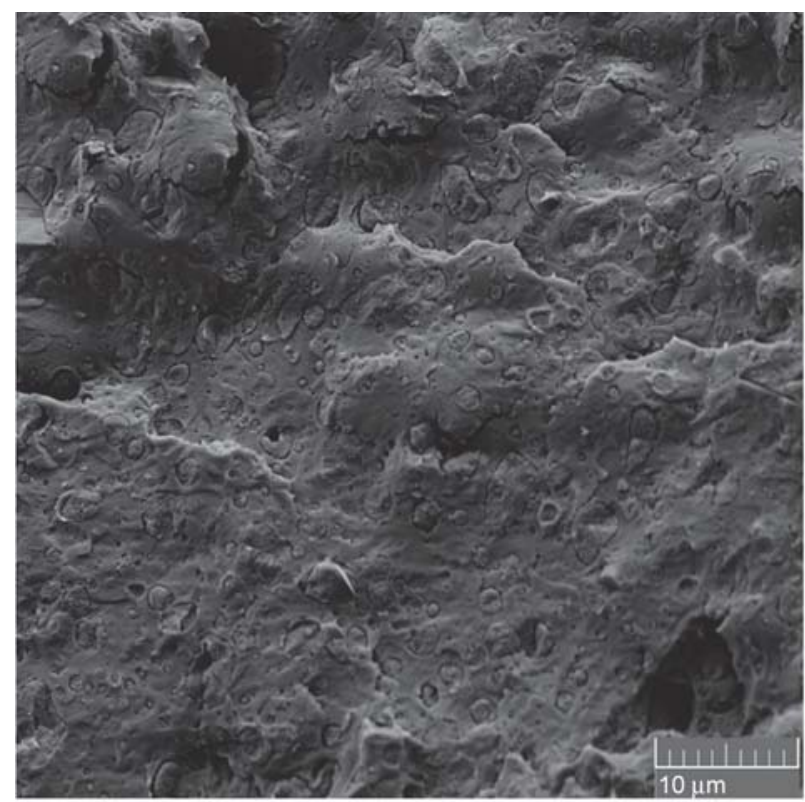

a)

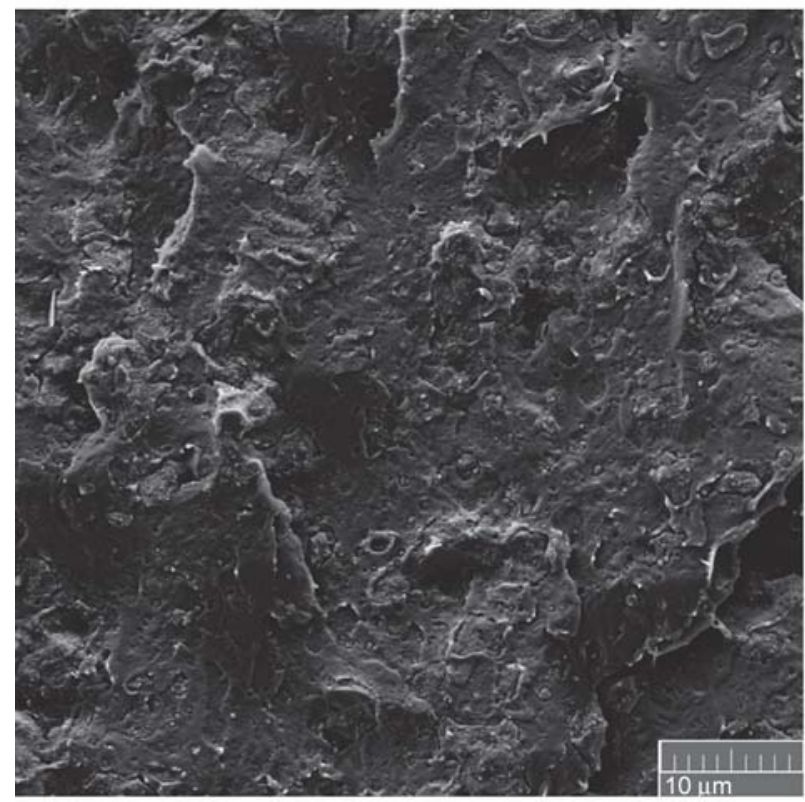

c)

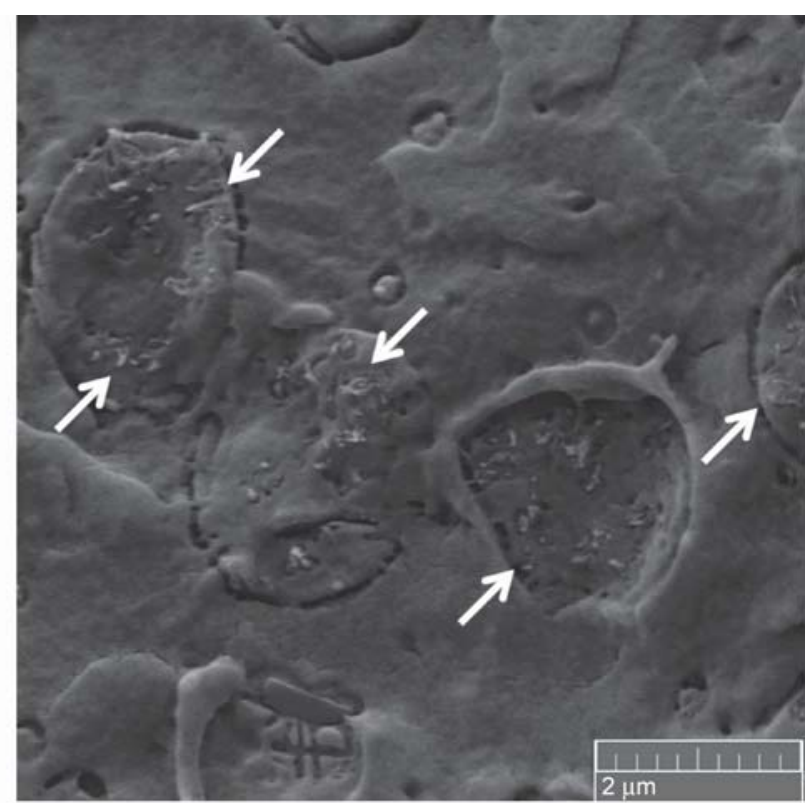

b)

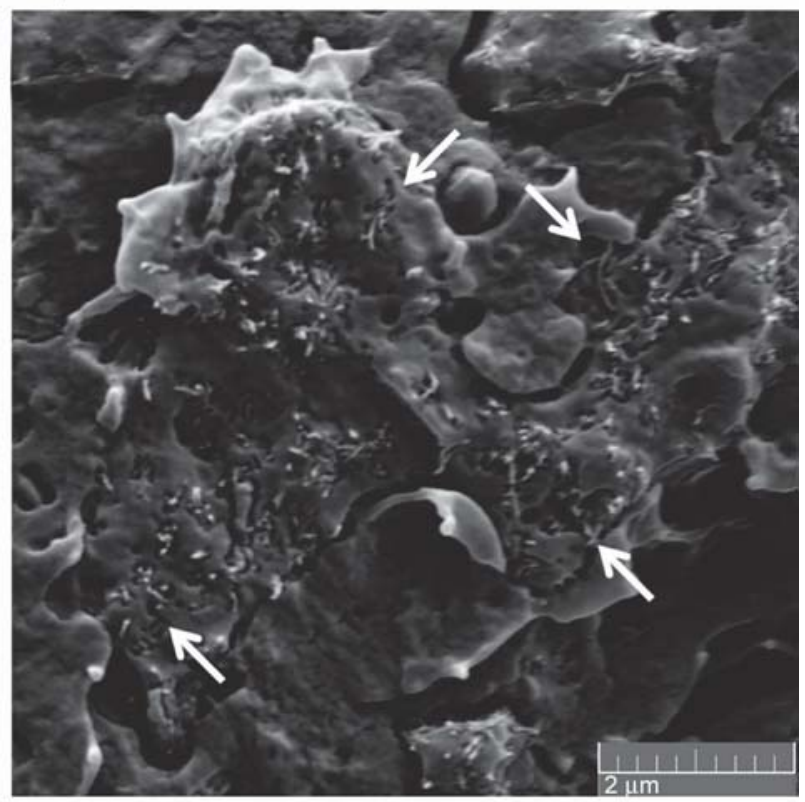

d)

Figure 2. FEG-SEM micrographs of (a), (b) PLA/PHBV/0.5CNT, and (c), (d) PLA/PHBV/1.0CNT blends-based nanocomposites.

clearly observed. In these micrographs, it was not possible to observe and verify if the CNT were also in the PLA matrix, even in a lower concentration.

The selective location of nanofiller in PLA blends was also verified by other authors. Urquijo et al. [15], for example, studied the preparation of PLA/ PCL blend nanocomposites with multiwalled carbon nanotube (CNT) contents ranged between 0.8 and $5.0 \mathrm{wt} \%$. The authors also observed (through transmission electron microscopy (TEM)) the selective location of the CNT in the PCL phase and the presence of less CNT in the PLA phase and in the PLAPCL interface. The selective location was attributed to the lower PCL-CNT interfacial tension compared to the PLA-CNT interfacial tension. The authors also observed that the addition of CNT causes changes in the morphology of the blends, more specifically in the PCL domains. With the increase in the concentration of CNT, the PCL domains, due to their coalescence, increased their size and changed their shape (less spherical). The same modification was observed for the PHBV domains in $\mathrm{PLA} / \mathrm{PHBV} / 1.0 \mathrm{CNT}$ nanocomposite (Figure 2d) when compared to the PLA/ PHBV/0.5CNT nanocomposite (Figure 2b), and the PLA/PHBV blend (Figure 1b). 


\subsection{Surface energy measurements}

The surface energy values were calculated using the contact angle data in Equation (2) and Equation (3), according to the geometric mean and the harmonic mean (Table 1). With the values of surface energy and using Equations (4) and (5), Equation (6) and Equation (1) were calculated: the interfacial energy with the harmonic and geometric mean, the spreading coefficient, and the wetting coefficient, respectively (Table 2). The negative spreading coefficient value ( -0.60 and -0.66$)$ between PLA and PHBV suggests, according to the theory, that the polymers are immiscible, which agrees with the morphology analysis (Figure 1) [58]. Comparing the values of interfacial energy (a lower value was observed between PHBV-CNT than between PLA-CNT) and the value obtained from the wetting coefficient (it was less than -1 ), the theory predicts that the particle should be located in the PHBV matrix [63]. Such theoretical results of the preferential location of the CNT in the PHBV matrix are in agreement and justify the

Table 1. Contact angles and surface energy of the components blend nanocomposite.

\begin{tabular}{|l|c|c|c|c|c|}
\hline \multirow{2}{*}{ Sample } & \multicolumn{2}{|c|}{$\begin{array}{c}\text { Contact angle } \\
{\left[{ }^{\circ}\right]}\end{array}$} & \multicolumn{3}{c|}{$\begin{array}{c}\text { Surface energy } \\
{[\mathbf{m N} / \mathbf{m}]}\end{array}$} \\
\cline { 2 - 6 } & $\mathbf{H}_{\mathbf{2}} \mathbf{O}$ & $\mathbf{C H}_{2} \mathbf{I}_{\mathbf{2}}$ & $\gamma_{\mathrm{s}}$ & $\gamma_{\mathbf{s}}^{\mathbf{d}}$ & $\gamma_{\mathrm{s}}^{\mathbf{p}}$ \\
\hline \multirow{2}{*}{ PLA } & \multirow{2}{*}{68.98} & \multirow{2}{*}{30.98} & $48.91^{\mathrm{a}}$ & $41.57^{\mathrm{a}}$ & $7.34^{\mathrm{a}}$ \\
\cline { 4 - 6 } & & $54.98^{\mathrm{b}}$ & $41.95^{\mathrm{b}}$ & $13.03^{\mathrm{b}}$ \\
\hline \multirow{2}{*}{ PHBV } & \multirow{2}{*}{67.35} & \multirow{2}{*}{39.71} & $48.39^{\mathrm{a}}$ & $39.76^{\mathrm{a}}$ & $8.63^{\mathrm{a}}$ \\
\cline { 4 - 6 } & \multicolumn{2}{|c|}{$[61]$} & $54.42^{\mathrm{b}}$ & $40.29^{\mathrm{b}}$ & $14.13^{\mathrm{b}}$ \\
\hline \multirow{2}{*}{ CNT } & \multicolumn{2}{|c|}{$[62]$} & 27.8 & 18.4 & 26.9 \\
\cline { 2 - 6 } & \multicolumn{2}{|c|}{} & & & 10.2 \\
\hline
\end{tabular}

${ }^{\mathrm{a}}$ Geometric-mean

bHarmonic-mean.

Table 2. Interfacial energy, wetting coefficient, and spreading coefficient between polymers and CNT using harmonic-mean and geometric-mean.

\begin{tabular}{|l|c|c|}
\hline \multicolumn{1}{|c|}{ Component } & $\begin{array}{c}\text { Harmonic-mean } \\
\text { equation } \\
\text { [mN/m] }\end{array}$ & $\begin{array}{c}\text { Geometric-mean } \\
\text { equation } \\
\text { [mN/m] }\end{array}$ \\
\hline $\mathrm{PLA} / \mathrm{PHBV}$ & 0.09 & 0.08 \\
\hline $\mathrm{PLA} / \mathrm{CNT}^{\mathrm{a}}$ & 14.01 & 10.79 \\
\hline $\mathrm{PLA} / \mathrm{CNT}^{\mathrm{b}}$ & 10.31 & 5.31 \\
\hline $\mathrm{PHBV} / \mathrm{CNT}^{\mathrm{a}}$ & 12.16 & 9.11 \\
\hline${\mathrm{PHBV} / \mathrm{CNT}^{\mathrm{b}}}^{\mathrm{a}}$ & 9.54 & 4.53 \\
\hline \multirow{2}{*}{$\omega_{\mathrm{a}}$} & $-20.56^{\mathrm{a}}$ & $-21.00^{\mathrm{a}}$ \\
\hline$\lambda_{\mathrm{ij}}$ & $-8.56^{\mathrm{b}}$ & $-9.75^{\mathrm{b}}$ \\
\hline
\end{tabular}

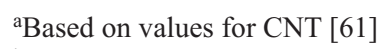

${ }^{\mathrm{b}}$ Based on values for CNT [62]. results observed in the micrograph obtained in the FEG-SEM (Figure 2).

Other works $[12,66,67]$ have also observed the selective localization of the particle through theoretical values and micrographs of nanocomposites from PLA blends. Arroyo and Ryan [66] also proved theoretically and experimentally the immiscibility of the blend and the preference of the particle for one of the phases in the PHBV/PLA (80/20) blend-based composite with the addition of carbon black (CB). The value of the interfacial tension between PHBV$\mathrm{CB}$ was lower $(5.187 \mathrm{mN} / \mathrm{m})$ than between PLA-CB $(8.682 \mathrm{mN} / \mathrm{m})$, which suggested (theoretical values), and it was proven (by SEM micrograph analysis) the preferential localization of the $\mathrm{CB}$ by the PHBV phase of the blend. Whereas in the PLA/PHBV/TiO blend nanocomposites, the preferred location of the nanoparticle was by the PLA phase, observed in the TEM micrographs, where it was justified by the lower value of interfacial tension between $\mathrm{PLA}-\mathrm{TiO}_{2}$ $(1.98 \mathrm{mN} / \mathrm{m})$ than between $\mathrm{PHBV}_{-\mathrm{TiO}_{2}}(4.27 \mathrm{mN} / \mathrm{m})$. The value obtained from the wetting coefficient indicated that the nanoparticles should be present in PLA phase and perhaps in the interphase, which also was confirmed by the analysis of the TEM micrograph [12]. Xiu et al. [67] observed the location of $\mathrm{TiO}_{2}$ nanoparticles in the interface of the PLA/poly (ether)urethane (PU) blend. The wetting coefficient value in the geometric-mean equation was 0.55 , and for the harmonic-mean equation 0.08 , a value that indicated the selective location for the PLA-PU interface, as evidenced by SEM micrographs.

\subsection{Thermal properties: DSC and TGA}

For the DSC analysis, the samples were previously heated to eliminate the thermal history (of the processing) and were subsequently cooled. Figure 3a shows the cooling curves obtained in the DSC analyses of the neat polymers, PLA/PHBV blend, PLA/ PHBV/0.5CNT, and PLA/PHBV/1.0CNT nanocomposites, where it was possible to observe the crystallization temperature $\left(T_{\mathrm{c}}\right)$ in all samples. The $T_{\mathrm{c}}$ of the PHBV is not visible in the cooling curve for the PLA/ PHBV blend (peak at $122^{\circ} \mathrm{C}$ ). However, the addition of 0.5 and $1.0 \mathrm{wt} \%$ of $\mathrm{CNT}$ in the nanocomposites intensifies the crystallization process of $\mathrm{PHBV}$, and the peak at $122{ }^{\circ} \mathrm{C}$ becomes quite evident. The presence of this peak was also observed by Montanheiro et al. [39] in PHBV/CNT nanocomposites, which verified that $\mathrm{CNT}$ acts as a nucleating agent promoting 

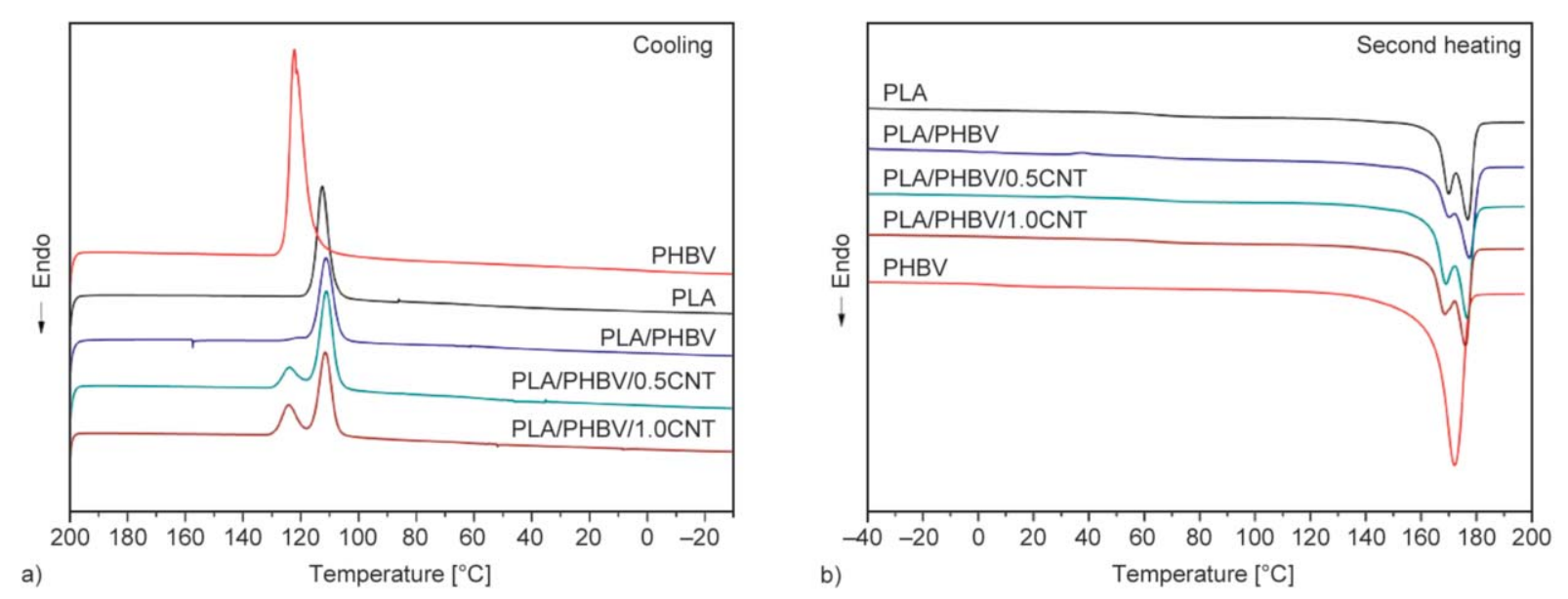

Figure 3. DSC curves of the neat PLA, neat PHBV, PLA/PHBV blend, PLA/PHBV/0.5CNT and PLA/PHBV/1.0CNT: (a) cooling, and (b) second heating.

the previous crystallization of PHBV. In this way, this result corroborates with the analysis of the morphology of the PLA/PHBV blends-based nanocomposites (Figure $2 \mathrm{~b}$ and Figure $2 \mathrm{~d}$ ) in which the CNTs are located in the PHBV domain in the nanocomposites. Figure $3 \mathrm{~b}$ shows the second heating curve of the samples. According to the results for the neat PHBV only one melting temperature peak $\left(172^{\circ} \mathrm{C}\right)$ was observed, whereas for neat PLA, two peaks were observed $\left(170\right.$ and $\left.177^{\circ} \mathrm{C}\right)$. The PLA behavior can be attributed to the two distributions of spherulites, of greater and lesser thermal stability. These peaks are characteristic of the PLA which has two stereoisomers (D-isomer and L-isomer) with different melting temperature $\left(T_{\mathrm{m}}\right)$ values $[8,68]$. It is also noted that the endothermic peaks of neat polymers are presented in the same temperature region. For the PLA/PHBV blend and for the PLA/PHBV/0.5CNT and PLA/ PHBV/1.0CNT nanocomposites, two endothermic peaks $\left(\sim 169\right.$ and $\left.177^{\circ} \mathrm{C}\right)$ were also observed. Table 3 shows the values of glass transition temperature $\left(T_{\mathrm{g}}\right)$, $T_{\mathrm{m}}$, and melting enthalpy $\left(\Delta H_{\mathrm{m}}\right)$ obtained in the second heating for the samples.

The PLA/PHBV blend during the second heating showed two values of $T_{\mathrm{g}}$, indicating the immiscibility of the polymers in the blend. This result corroborates with the images observed in FEG-SEM analyses (Figure 1) and the surface energy measurements (Table 2). DSC curves of the second heating amplification area can be seen in Figure 4, showing better the region of the $T_{\mathrm{g}}$ of samples. The $T_{\mathrm{g}}$ of neat PLA $\left(64^{\circ} \mathrm{C}\right)$ did not change significantly in the PLA/ PHBV blend, which showed one $T_{\mathrm{g}}$ values similar to the neat polymer in $66^{\circ} \mathrm{C}$. Meanwhile, the $T_{\mathrm{g}}$ value of PHBV $\left(5^{\circ} \mathrm{C}\right)$ had a small decrease to $-2{ }^{\circ} \mathrm{C}$ in the blend and nanocomposite. The decreasing of $T_{\mathrm{g}}$ verified in the PHBV can indicate that there is an interaction between PHBV and PLA. In the case of nanofiller addition, it is usual to verify no changes in $T_{\mathrm{g}}$ because there is no interaction at the molecular level.

It can be noted in Table 3 that the neat PLA (170 and $\left.177^{\circ} \mathrm{C}\right)$ and the neat PHBV $\left(172^{\circ} \mathrm{C}\right)$ have the same range of $T_{\mathrm{m}}$, and consequently, the peaks related to these temperatures overlap in the curve of the PLA/ PHBV blend and the nanocomposites (Figure 3b). Therefore, it is difficult to determine the degree of crystallinity $\left(X_{\mathrm{c}}\right)$ of the blend in relation to each polymer using the DSC analysis. The addition of CNT did not alter the thermal behavior of PLA/PHBV/CNT

Table 3. Thermal properties of the neat polymers, PLA/PHBV blend, and PLA/PHBV/CNT nanocomposites cooling and second heating.

\begin{tabular}{|l|c|c|c|c|c|c|c|}
\hline \multicolumn{1}{|c|}{ Sample } & $\begin{array}{c}\boldsymbol{T}_{\mathbf{c 1}} \\
{\left[{ }^{\circ} \mathbf{C}\right]}\end{array}$ & $\begin{array}{c}\boldsymbol{T}_{\mathbf{c} 2} \\
{\left[{ }^{\circ} \mathbf{C}\right]}\end{array}$ & $\begin{array}{c}\boldsymbol{T}_{\mathbf{g} 1} \\
{\left[{ }^{\circ} \mathbf{C}\right]}\end{array}$ & $\begin{array}{c}\boldsymbol{T}_{\mathbf{g} 2} \\
{\left[{ }^{\circ} \mathbf{C}\right]}\end{array}$ & $\begin{array}{c}\boldsymbol{T}_{\mathbf{m} 1} \\
{\left[{ }^{\circ} \mathbf{C}\right]}\end{array}$ & $\begin{array}{c}\boldsymbol{T}_{\mathbf{m} 2} \\
{\left[{ }^{\circ} \mathbf{C}\right]}\end{array}$ & $\begin{array}{c}\Delta \boldsymbol{H}_{\mathbf{m}} \\
{[\mathbf{J} / \mathbf{g}]}\end{array}$ \\
\hline PLA & - & 112 & - & 64 & 170 & 177 & 44.27 \\
\hline PHBV & 122 & - & 5 & - & 172 & - & 92.82 \\
\hline PLA/PHBV & - & 112 & -2 & 66 & 169 & 177 & 44.11 \\
\hline PLA/PHBV/0.5CNT & 122 & 112 & -2 & 63 & 169 & 177 & 55.45 \\
\hline PLA/PHBV/1.0CNT & 122 & 112 & -2 & 64 & 168 & 176 & 48.10 \\
\hline
\end{tabular}



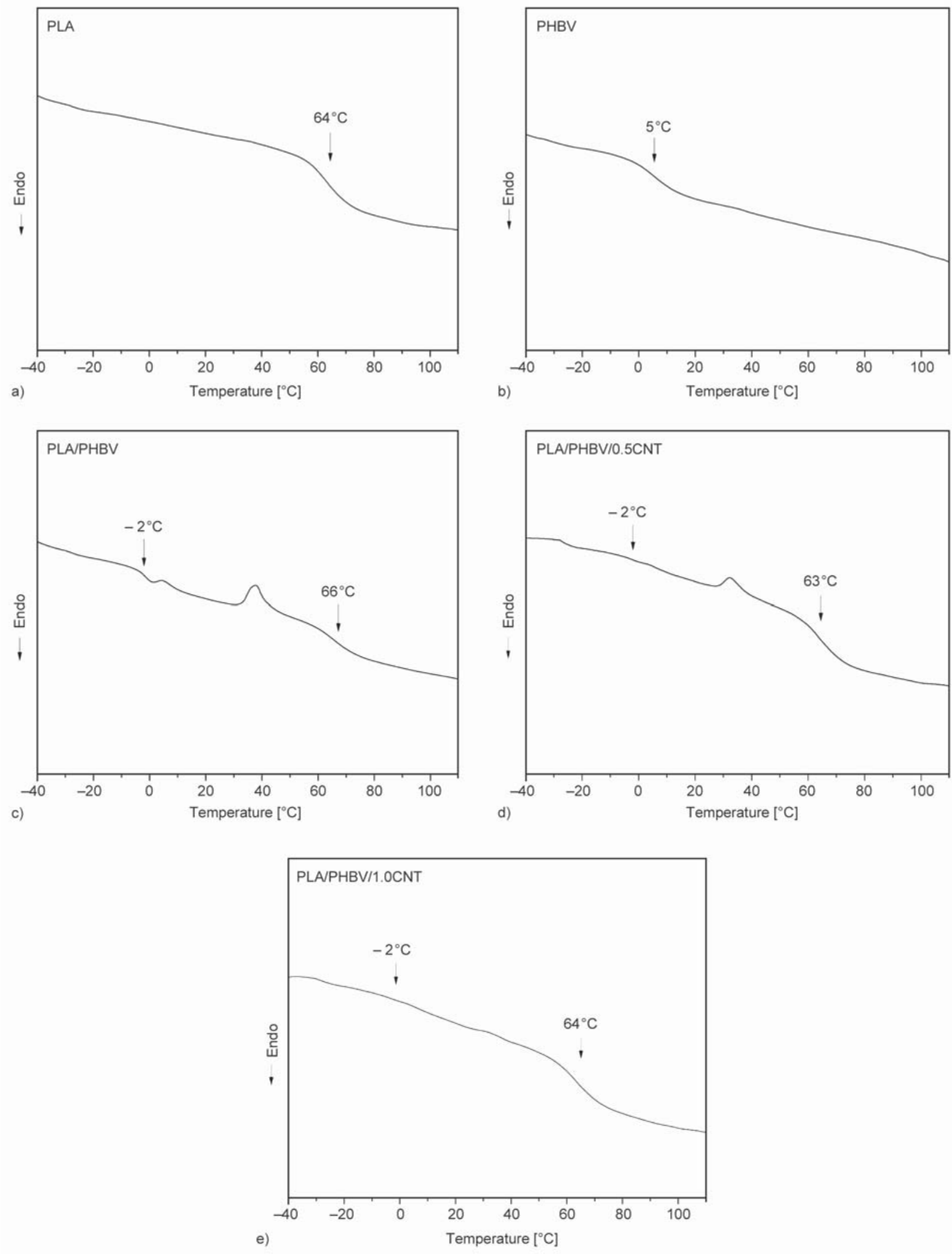

Figure 4. DSC curves of the second heating with amplification in the area of the $T_{\mathrm{g}}$ of (a) neat PLA, (b) neat PHBV, (c) PLA/PHBV blend, (d) PLA/PHBV/0.5CNT, and (e) PLA/PHBV/1.0CNT nanocomposites.

nanocomposites when compared with PLA/PHBV blend. However, when the $\Delta \mathrm{Hm}$ values are analyzed (Table 3), there is an increase in the $\Delta H_{\mathrm{m}}$ value for
PLA/PHBV/CNT nanocomposites when compared to the PLA/PHBV blend. As the $\Delta H_{\mathrm{m}}$ is related to the $X_{\mathrm{c}}$ of the polymers, this increase in the enthalpy 
of the nanocomposites can indicate an increase in $X_{\mathrm{c}}$, which is yet another indication of the nucleating action of CNT in the nanocomposites.

The variation of $\Delta H_{\mathrm{m}}$ does not vary systematically with CNT content because the CNT distribution is not homogeneous in the PLA/PHBV (80:20) blend. The variation of $\Delta H_{\mathrm{m}}$ is more affected by the polymer that is in a greater proportion, i.e., PLA matrix. However, the SEM images showed that CNTs are more incorporated into PHBV domains. Therefore, the increase of CNTs load in the nanocomposite does not result in a systematic increase in both polymer phases. So, as the CNTs concentration in the PLA matrix is proportionally less than the addition, the variation of $\Delta H_{\mathrm{m}}$ does not vary systematically.

Figure 5 and Table 4 show the TGA curves and the TGA results of the neat polymers, PLA/PHBV blend, PLA/PHBV/0.5CNT, and PLA/PHBV/1.0CNT nanocomposites. The neat polymers showed only one step of thermal degradation, and the Tonset occurs at $285^{\circ} \mathrm{C}$ for the neat PHBV, and at $347^{\circ} \mathrm{C}$ for neat PLA (Table 4), which shows that PLA is more thermostable
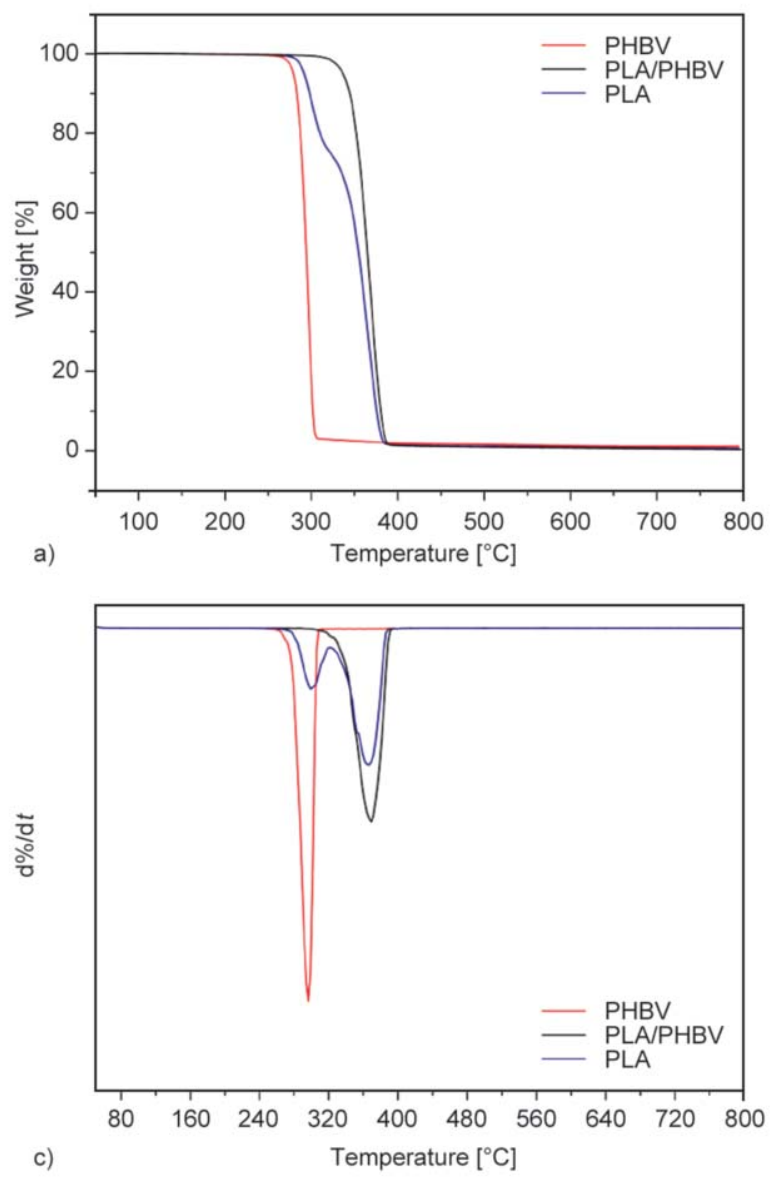

Table 4. Thermal decomposition temperatures of neat polymers, PLA/PHBV blend and PLA/PHBV/CNT nanocomposites.

\begin{tabular}{|l|c|c|}
\hline \multicolumn{1}{|c|}{ Samples } & $\begin{array}{l}\boldsymbol{T}_{\text {onset }} \\
{\left[{ }^{\circ} \mathbf{C}\right]}\end{array}$ & $\begin{array}{l}\boldsymbol{T}_{\max } \\
{\left[{ }^{\circ} \mathbf{C}\right]}\end{array}$ \\
\hline PLA & 347 & 382 \\
\hline PHBV & 285 & 303 \\
\hline PLA/PHBV & 287 & 379 \\
\hline PLA/PHBV/0.5CNT & 287 & 379 \\
\hline PLA/PHBV/1.0CNT & 290 & 380 \\
\hline
\end{tabular}

than PHBV. According to Aoyagi et al. [69], the thermal degradation of the polymers occurs by transesterification. For PHBV, in addition to transesterification, there is also the process of elimination of $\beta$-hydrogen or cis-elimination.

The PLA/PHBV presents two-step thermal degradation referring to the content of the PLA and PHBV in the blend (Figure 5a). These steps of thermal degradation are confirmed in Figure $5 \mathrm{c}$, which shows the first derivative curves of the thermogravimetric analysis. The first step of thermal degradation of the PLA/PHBV blend is referent to the PHBV, and the
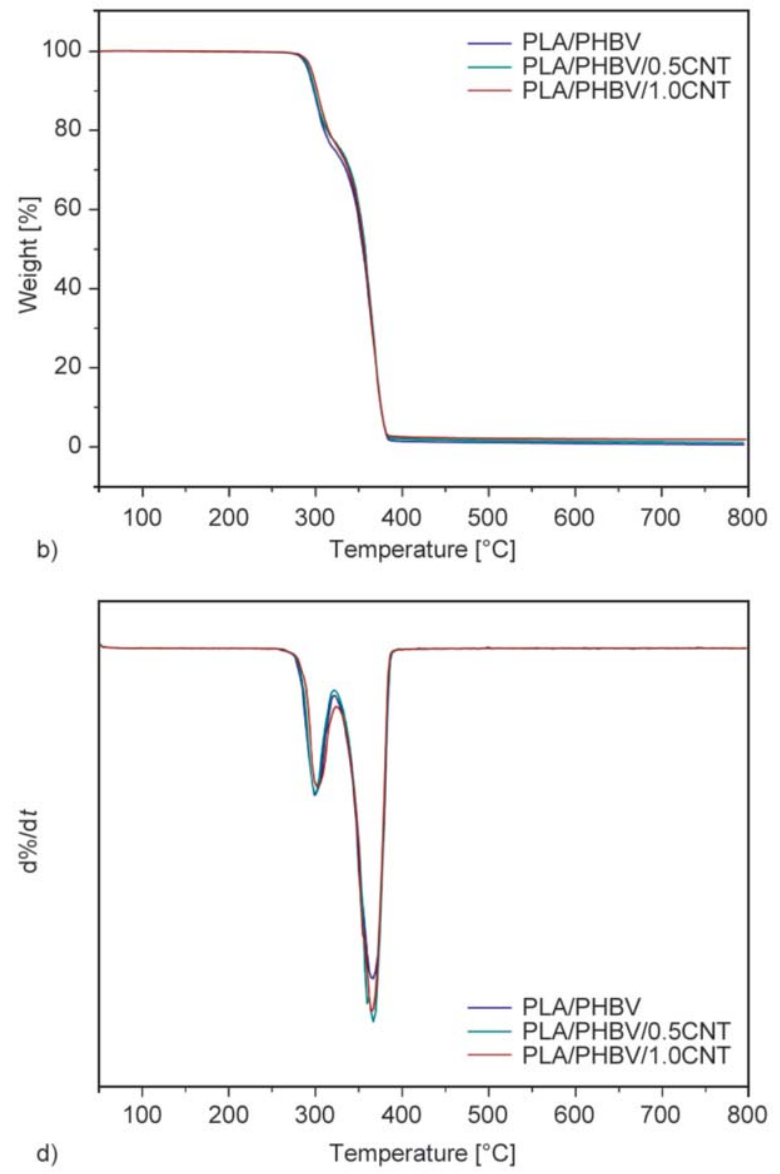

Figure 5. Thermal degradation of the PLA, PHBV polymers, PLA/PHBV blend (a) and nanocomposites (b) thermogravimetric curves; (c) and (d) first derivative curves. 
second thermal step is to the PLA. These results also were observed by Modi et al. [11] and Mofokeng and Luyt [12].

The addition of 0.5 and $1.0 \mathrm{wt} \%$ of CNT did not significantly change the thermal degradation of the PLA/ PHBV/CNT nanocomposites (Figure 5d when compared with the PLA/PHBV blend (Figure $5 \mathrm{~b}$ and Table 4). Then, the addition of CNT does not modify the thermal degradation behavior.

\subsection{Mechanical properties: Impact strength and flexural tests}

Table 5 shows the impact strength, flexural yield strength, and flexural modulus results of neat polymers, PLA/PHBV blend, and nanocomposites. The neat polymers (PLA and PHBV) present the same Izod impact strength values. Nevertheless, the PHBV domains dispersed in the PLA matrix presented a toughness action in the PLA/PHBV blend, increasing the impact resistance by $91.6 \%$ when compared to neat PLA. The increase in toughness in the composition of the PLA/PHBV (80/20) blend was also observed by Ma et al. [17] and Gerard et al. [16]. The improvement in the impact strength may be associated with a good interaction of polymers in the blend, which allowed the load distribution to be effective, resulting in an improvement in the fracture toughness of this composition compared to neat PLA.

The impact strength values for PLA/PHBV/0.5CNT and PLA/PHBV/1.0CNT nanocomposites also showed very close values. The PLA/PHBV/0.5CNT and PLA/PHBV/1.0CNT nanocomposites showed a decrease of 43 and $40 \%$, respectively, in the impact strength values compared to the PLA/PHBV blend. This decrease in the impact strength may have been caused by the increase in the hardness of the toughening phase with the presence of CNT. As the CNT was preferentially located in the PHBV phase, the phase became stiffer, and thus the toughening effect of PHBV in the blend decreased [27, 70]. Another factor for the decrease in the impact strength can be caused by the formation of CNT clusters in the PHBV domains and possibly in the interface of the polymer blend, which probably impaired the toughness action of the PHBV domain by causing changes in the morphology of the blend nanocomposites. As there was no sharing of the stress applied to the material, the nanoparticles may have acted as stress concentrating agents, that is, defects in the matrix, thus reducing the impact strength. Montanheiro et al. [71] observed a reduction in the impact strength for PHBV/CNT nanocomposites which was justified by the poor dispersion of the nanofiller in the matrix acting as stress concentrators.

PLA showed the flexural yield strength values greater than PHBV and without significant difference with the values of PLA/PHBV blend (Table 5). The values obtained in the flexural test were statistically analyzed using the analysis of variance (ANOVA) with a $95 \%$ confidence interval. As for the flexural modulus, the neat PLA presented a lower value than the neat PHBV, and the addition of PHBV in the PLA/ PHBV blend increased the value of the flexural modulus when compared to the PLA. This behavior is an indication that the addition and good distribution of the PHBV domains in the PLA matrix proved to be efficient to improve the final mechanical property of the blend. In Table 5, it can be observed that the addition of 0.5 and $1.0 \mathrm{wt} \%$ of CNT in the nanocomposites did not cause significant changes in the flexural yield strength and flexural modulus when compared with the PLA/PHBV blend.

Such results can be justified by the selective localization of the CNT in the PHBV and the formation of agglomerates of CNT in the blend nanocomposite, which was observed in the FEG-SEM micrograph (Figure 2). Consequently, the stress applied during the mechanical bending test was not effectively transmitted between the matrix (blend) and the reinforcing nanofillers (CNT) in the nanocomposites. Dasan et al. [21] observed a decrease in the flexural modulus and flexural strength with an increase in the $\mathrm{CNC}$

Table 5. Values of Izod impact test and flexural test: neat polymers, PLA/PHBV blend, and PLA/PHBV/CNT nanocomposites.

\begin{tabular}{|l|c|c|c|}
\hline \multicolumn{1}{|c|}{ Sample } & $\begin{array}{c}\text { Izod impact strength } \\
{\left[\mathbf{k J} / \mathbf{m}^{2}\right]}\end{array}$ & $\begin{array}{c}\text { Flexural yield strength } \\
{[\mathbf{M P a}]}\end{array}$ & $\begin{array}{c}\text { Flexural modulus } \\
{[\mathbf{G P a}]}\end{array}$ \\
\hline PLA & $2.14 \pm 0.05$ & $58.07 \pm 2.77$ & $2.94 \pm 0.07$ \\
\hline PHBV & $1.99 \pm 0.16$ & $47.70 \pm 2.12$ & $3.48 \pm 0.20$ \\
\hline PLA/PHBV & $4.10 \pm 0.20$ & $51.60 \pm 5.30$ & $3.10 \pm 0.10$ \\
\hline PLA/PHBV/0.5CNT & $2.33 \pm 0.15$ & $58.66 \pm 6.74$ & $3.30 \pm 0.08$ \\
\hline PLA/PHBV/1.0CNT & $2.46 \pm 0.30$ & $61.01 \pm 4.48$ & $3.25 \pm 0.24$ \\
\hline
\end{tabular}


contents $(>0.75 \mathrm{wt} \%))$ in the PLA/PHBV blend. The decrease of the property was attributed to the increased agglomeration and low dispersion of CNT in the blend.

\subsection{Electrical conductivity}

Table 6 shows the electrical conductivity of the PLA/ PHBV blend, PLA/PHBV/0.5CNT, and PLA/PHBV/ 1.0CNT nanocomposites. Analyzing the electrical conductivity value of the PLA/PHBV blend, it can be observed that the blend presents an insulating material behavior. PLA and PHBV are insulating materials; consequently, the blend also exhibits insulating behavior [15, 42].

The addition of a small content of CNT $(0.5$ and $1.0 \mathrm{wt} \%$ ) increased the electrical conductivity of the PLA/PHBV blend. The increase was expressive, in which the nanocomposites presented values of electrical conductivity of semiconductor materials and no more behavior of insulating material [6]. The addition of $0.5 \mathrm{wt} \%$ of CNT increases 6 orders of magnitude, and the addition of $1 \mathrm{wt} \%$ of CNT increases 12 orders of magnitude when compared to the PLA/ PHBV blend. Cui et al. [38] obtained electrical conductivity equal to $3.62 \cdot 10^{-3} \mathrm{~S} / \mathrm{m}$ for the PLA nanocomposite with $0.60 \%$ of CNT.

Similar observations have been made in other PLA/ CNT nanocomposites. Quan et al. [37] and Kuan et al. [34] observed an increase in electrical conductivity for PLA/CNT nanocomposites with the addition of up to $2.0 \mathrm{wt} \% \mathrm{CNT}$, in which the nanocomposites began to have a behavior of semiconductor materials. The authors have reported that a good dispersion of the CNT effectively influenced the improvement of the electrical properties since conducting networks were formed in the nanocomposite. Urquijo et al. [15] verified that the addition of CNT improved the electrical conductivity of the PLA/PCL blend (composition 80:20) from $10^{-13}$ to $10^{-7} \mathrm{~S} / \mathrm{cm}$ with $2.0 \mathrm{wt} \%$, and $10^{-6} \mathrm{~S} / \mathrm{cm}$ with $4.0 \mathrm{wt} \% \mathrm{CNT}$. In these systems, the CNTs were selectively located at the PCL phase, and in less quantity at the PLA/PCL interface, and in the PLA phase. The improvement in the electrical conductivity was attributed to the formation of an almost continuous network of CNT for compositions above $2.0 \mathrm{wt} \% \mathrm{CNT}$.

FEG-SEM images (Figure 2) indicated that CNTs are preferentially located in the PHBV domains that are dispersed in the PLA matrix. However, the improvement in the electrical properties of the nanocomposites
Table 6. Electrical conductivity values of the PLA/PHBV blend, PLA/PHBV/0.5CNT, and PLA/PHBV/ 1.0CNT blend nanocomposites.

\begin{tabular}{|l|c|}
\hline \multicolumn{1}{|c|}{ Samples } & $\begin{array}{c}\text { Electrical conductivity } \\
{[\mathbf{S} / \mathbf{m}]}\end{array}$ \\
\hline PLA/PHBV & $8.67 \cdot 10^{-14}$ \\
\hline PLA/PHBV/0.5CNT & $6.19 \cdot 10^{-8}$ \\
\hline PLA/PHBV/1.0CNT & $2.79 \cdot 10^{-2}$ \\
\hline
\end{tabular}

can suggest that CNT may also be present in a smaller quantity in the PLA phase. Thus, with the CNT dispersed in the nanocomposite, it was possible to form conducting networks to facilitate the electrical conductivity in the material.

\subsection{Reflectivity measurements}

Electromagnetic behavior of PLA/PHBV blend and PLA/PHBV/CNT nanocomposites was evaluated by reflectivity $[\mathrm{dB}]$ as a function of frequency $[\mathrm{GHz}]$, Figure 6 . The measures were performed in the frequency range of 8.2 to $12.4 \mathrm{GHz}$ (X-band) of the electromagnetic spectrum, a range of great commercial and military importance.

For the PLA/PHBV blend, the behavior of a transparent material to the incident radiation was observed, with the reflectivity curve coincident with the curve of the metal plate (reflective material) in the frequency range evaluated $(8.2-12.4 \mathrm{GHz})$. This behavior was already expected since the blend behaves as an insulating material, i.e., did not present adequate electrical conductivity. In this case, the incident radiation goes through the polymer material (PLA/ PHBV blend), coincides with the metal plate (in the waveguide), and again is reflected back to the incidence surface of the wave.

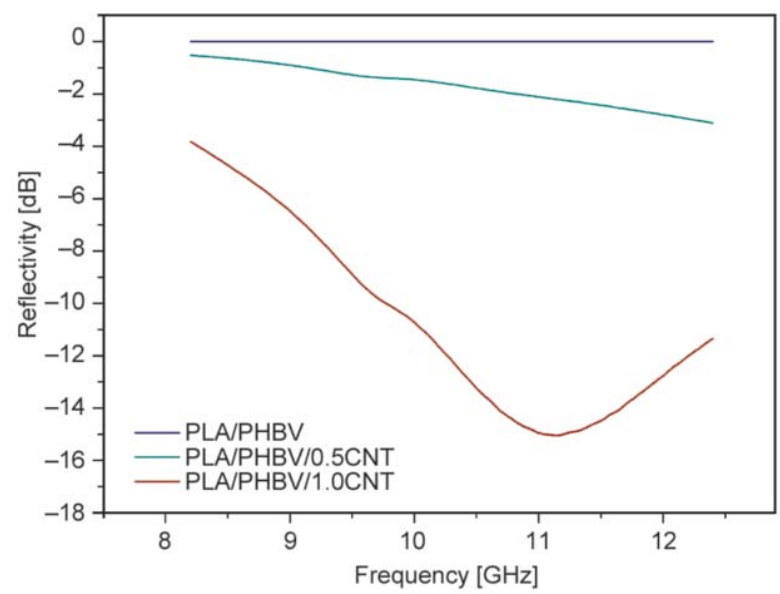

Figure 6. Reflectivity curves versus frequency of the PLA/ PHBV blend, PLA/PHBV/0.5CNT, and PLA/ PHBV/1.0CNT nanocomposites. 
The PLA/PHBV/0.5CNT nanocomposites showed a higher radiation attenuation value at $12.4 \mathrm{GHz}$, of the order of $-3 \mathrm{~dB}$, compared to the PLA/PHBV blend. In the curve of PLA/PHBV/0.5CNT nanocomposite, the increase in attenuation with increasing frequency (up to $12.4 \mathrm{GHz}$ ) was observed. Thus, with this CNT proportion in the blend nanocomposite noted that $50 \%$ of the radiation is absorbed by the material [72]. The PLA/PHBV/1.0CNT nanocomposites showed attenuation value up to $-15 \mathrm{~dB}$ around $11 \mathrm{GHz}$, where approximately $96.9 \%$ of the radiation is attenuated $[72,73]$. For this nanocomposite, an increase in the attenuation of the radiation with the increase of the frequency until $11 \mathrm{GHz}$ is observed; above this range, it is observed the reduction in the attenuation until 12.4 GHz. Cui et al. [38] obtained an attenuation value of $-18.4 \mathrm{~dB}$ for PLA/CNT nanocomposite with the addition of $1.0 \mathrm{wt} \% \mathrm{CNT}$. Good attenuation values can be achieved for conductive materials, which may favor mechanisms of loss of incident radiation, as observed for the blends with the addition of $1.0 \mathrm{wt} \%$ CNT. At this concentration, the PLA/ PHBV/1.0CNT nanocomposite shows promise as a radar-absorbing material with potential application in the civil and military sectors, in this latter case, contributing to the stealth of military targets exposed to radar tracking $[72,74]$.

\section{Conclusions}

Biodegradable nanocomposites based on PLA/PHBV blend reinforced with different contents of carbon nanotubes have been successfully prepared and presented interesting properties for electronic devices and military sectors. FEG-SEM micrographs of the PLA/PHBV/0.5CNT and PLA/PHBV/1.0CNT nanocomposites showed that CNTs were preferentially located in the PHBV phase, confirming the data obtained theoretically through the surface energy measurements. CNT promoted the previous crystallization of the PHBV in the cooling and did not affect the thermal stability of nanocomposites. The flexural yield strength and flexural modulus of the blend were not affected with the addition of CNT, but the Izod impact strength decreased, probably because CNT increased the stiffness of the PHBV phase and thus decreased the toughening effect. Despite the decrease, the values were not inferior to the impact resistance of PLA. The PLA/PHBV/CNT nanocomposites showed excellent values of electrical conductivity, being more expressive for the addition of $1.0 \mathrm{wt} \%$ of CNT. This improvement indicates that CNT is also present in the PLA phase of the blend. The addition of $1.0 \mathrm{wt} \% \mathrm{CNT}$ in the blend assigned good values of attenuation of the electromagnetic radiation in X-band (maximum of $\sim 97 \%$ around $11 \mathrm{GHz}$ ), showing the potential of this material as an absorber of electromagnetic radiation in the range of microwaves.

\section{Acknowledgements}

The authors would like to thank Laboratório de Cerâmicas Avançadas (LCA - UNIFESP) for impedance tests, the Instituto de Tecnologia Aeronáutica (ITA) for reflectivity measurements, the Instituto Nacional de Pesquisas Espaciais (INPE) for SEM-FEG images, the Federal University of São Carlos for DSC analysis and ALLTEC Indústria de Componentes em Materiais Compostos for flexural tests. This work was supported by the Coordenação de Aperfeiçoamento de Pessoal de Nível Superior (CAPES) - Finance Code-001. The authors acknowledge the financial support received from Fundação de Amparo à Pesquisa do Estado de São Paulo (FAPESP 2019/15976-0), and Conselho Nacional de Desenvolvimento Científico e Tecnológico (CNPq 313989/2018-4).

\section{References}

[1] Baldé C. P., Wang F., Kuehr R., Huisman J.: The global e-waste monitor 2014: Quantities, flows and resources. United Nations University, Bonn (2015).

[2] Nagarajan V., Mohanty A. K., Misra M.: Perspective on polylactic acid (PLA) based sustainable materials for durable applications: Focus on toughness and heat resistance. ACS Sustainable Chemistry and Engineering, 4, 2899-2916 (2016). https://doi.org/10.1021/acssuschemeng.6b00321

[3] Yu L., Dean K., Li L.: Polymer blends and composites from renewable resources. Progress in Polymer Science, 31, 576-602 (2006).

https://doi.org/10.1016/j.progpolymsci.2006.03.002

[4] Mehta R., Kumar V., Bhunia H., Upadhyay S. N.: Synthesis of poly(lactic acid): A review. Journal of Macromolecular Science Part C: Polymer Reviews, 45, 325349 (2005).

https://doi.org/10.1080/15321790500304148

[5] Raquez J-M., Habibi Y., Murariu M., Dubois P.: Polylactide (PLA)-based nanocomposites. Progress in Polymer Science, 38, 1504-1542 (2013). https://doi.org/10.1016/j.progpolymsci.2013.05.014

[6] Akbari A., Majumder M., Tehrani A.: Polylactic acid (PLA) carbon nanotube nanocomposites. in 'Handbook of polymer nanocomposites. Processing, performance and application' (eds.: Kar K. K., Pandey J. K., Rana S.) Springer, Berlin, 283-297 (2015). https://doi.org/10.1007/978-3-642-45229-1 45 
[7] Jamshidian M., Tehrany E. A., Imran M., Jacquot M., Desobry S.: Poly-lactic acid: Production, applications, nanocomposites, and release studies. Comprehensive Reviews in Food Science and Food Safety, 9, 552-571 (2010). https://doi.org/10.1111/j.1541-4337.2010.00126.x

[8] Larrañaga A., Lizundia E.: A review on the thermomechanical properties and biodegradation behaviour of polyesters. European Polymer Journal, 121, 109296/1109296/31 (2019).

https://doi.org/10.1016/j.eurpolymj.2019.109296

[9] Qazi R. A., Khan M. S., Shah L. A., Ullah R., Kausar A., Khattak R.: Eco-friendly electronics, based on nanocomposites of biopolyester reinforced with carbon nanotubes: A review. Polymer-Plastic Technology and Materials, 59, 928-951 (2020).

https://doi.org/10.1080/25740881.2020.1719137

[10] Hamad K., Kaseem M., Ayyoob M., Joo J., Deri F.: Polylactic acid blends: The future of green, light and tough. Progress in Polymer Science, 85, 83-127 (2018). https://doi.org/10.1016/j.progpolymsci.2018.07.001

[11] Modi S., Koelling K., Vodovotz Y.: Miscibility of poly (3-hydroxybutyrate-co-3-hydroxyvalerate) with high molecular weight poly(lactic acid) blends determined by thermal analysis. Journal of Applied Polymer Science, 124, 3074-3081 (2011).

https://doi.org/10.1002/app.35343

[12] Mofokeng J. P., Luyt A. S.: Morphology and thermal degradation studies of melt-mixed PLA/PHBV biodegradable polymer blend nanocomposites with $\mathrm{TiO}_{2}$ as filler. Journal of Applied Polymer Science, 132, 42138/1-42138/11 (2015).

https://doi.org/10.1002/app.42138

[13] de Aguiar J., Decol M., Pachekoski W. M., Becker D.: Mixing-sequence controlled selective localization of carbon nanoparticles in PLA/PCL blends. Polymer Engineering and Science, 59, 323-329 (2019).

https://doi.org/10.1002/pen.24908

[14] Decol M., Pachekoski W. M., Becker D.: Enhancing thermal conductivity and near-infrared radiation reflectance of poly( $\varepsilon$-caprolactone)/poly(lactic acid)-based nanocomposites by incorporating hexagonal boron nitride. Polymer Composites, 40, 3464-3471 (2019). https://doi.org/10.1002/pc.25208

[15] Urquijo J., Dagréou S., Guerrica-Echevarría G., Eguiazábal J. I.: Morphology and properties of electrically and rheologically percolated PLA/PCL/CNT nanocomposites. Jounal of Applied Polymer Science, 134, 45265/1-45265/10 (2017).

https://doi.org/10.1002/app.45265

[16] Gerard T., Budtova T., Podshivalov A., Bronnikov S.: Polylactide/poly(hydroxybutyrate-co-hydroxyvalerate) blends: Morphology and mechanical properties. Express Polymer Letters, 8, 609-617 (2014).

https://doi.org/10.3144/expresspolymlett.2014.64
[17] Ma P., Spoelstra A. B., Schmit P., Lemstra P. J.: Toughening of poly(lactic acid) by poly( $\beta$-hydroxybutyrateco- $\beta$-hydroxyvalerate) with high $\beta$-hydroxyvalerate content. European Polymer Journal, 49, 1523-1531 (2013). https://doi.org/10.1016/j.eurpolymj.2013.01.016

[18] Pinto V. C., Ramos T., Alves A. S. F., Xavier J., Tavares P. J., Moreira P. M. G. P., Guedes R. M.: Dispersion and failure analysis of PLA, PLA/GNP and PLA/CNT$\mathrm{COOH}$ biodegradable nanocomposites by SEM and DIC inspection. Engineering Failure Analysis, 71, 6371 (2017).

https://doi.org/10.1016/j.engfailanal.2016.06.009

[19] Park S. H., Lee S. G., Kim S. H.: Isothermal crystallization behavior and mechanical properties of polylactide/carbon nanotube nanocomposites. Composites Part A: Applied Science and Manufacturing, 46, 11-18 (2013). https://doi.org/10.1016/j.compositesa.2012.10.011

[20] Mai F., Deng H., Tu W., Chankajorn S., Fu Q., Bilotti E., Peijs T.: Oriented poly(lactic acid)/carbon nanotube composite tapes with high electrical conductivity and mechanical properties. Macromolecular Materials and Engineering, 300, 1257-1267 (2015). https://doi.org/10.1002/mame.201500163

[21] Dasan Y. K., Bhat A. H., Faiz A.: Polymer blend of PLA/PHBV based bionanocomposites reinforced with nanocrystalline cellulose for potential application as packaging material. Carbohydrate Polymers, 157, 13231332 (2017).

https://doi.org/10.1016/j.carbpol.2016.11.012

[22] Arrieta M. P., Fortunati E., Dominici F., López J., Kenny J. M.: Bionanocomposite films based on plasticized PLA-PHB/cellulose nanocrystal blends. Carbohydrate Polymers, 121, 265-275 (2015). https://doi.org/10.1016/j.carbpol.2014.12.056

[23] Raza Z. A., Abid S., Banat I. M.: Polyhydroxyalkanoates: Characteristics, production, recent developments and applications. International Biodeterioration and Biodegradation, 126, 45-56 (2018). https://doi.org/10.1016/j.ibiod.2017.10.001

[24] Alshehrei F.: Biodegradation of synthetic and natural plastic by microorganisms. Journal of Applied and Environmental Microbiology, 5, 8-19 (2017). https://doi.org/10.12691/jaem-5-1-2

[25] Li Z., Yang J., Loh X. J.: Polyhydroxyalkanoates: Opening doors for a sustainable future. NPG Asia Materials, 8, e265/1-e265/20 (2016).

https://doi.org/10.1038/am.2016.48

[26] Perić M., Putz R., Paulik C.: Influence of nanofibrillated cellulose on the mechanical and thermal properties of poly(lactic acid). European Polymer Journal, 114, 426-433 (2019). https://doi.org/10.1016/j.eurpolymj.2019.03.014 
[27] Lemes A. P., do Amaral Montanheiro T. L., da Silva A. P., Durán N.: PHBV/MWCNT films: Hydrophobicity, thermal and mechanical properties as a function of MWCNT concentration. Journal Composites Science, 3, 12/1-12/13 (2019).

https://doi.org/10.3390/jcs3010012

[28] Montanheiro T. L. A., Montagna L. S., Machado J. P. B., Lemes A. P.: Covalent functionalization of MWCNT with PHBV chains: Evaluation of the functionalization and production of nanocomposites. Polymer Composites, 40, 288-295 (2017).

https://doi.org/10.1002/pc.24644

[29] Verginio G. E. A., do Amaral Montanheiro T. L., Montagna L. S., Marini J., Passador F. R.: Effectiveness of the preparation of maleic anhydride grafted poly(lactic acid) by reactive processing for poly(lactic acid)/carbon nanotubes nanocomposites. Journal of Applied Polymer Science, 138, 50087/1-50087/11 (2020). https://doi.org/10.1002/app.50087

[30] Zare Y., Rhee K. Y.: Following the morphological and thermal properties of PLA/PEO blends containing carbon nanotubes (CNTs) during hydrolytic degradation. Composites Part B: Engineering, 175, 107132/1107132/13 (2019).

https://doi.org/10.1016/j.compositesb.2019.107132

[31] Kim S., Zare Y., Garmabi H., Rhee K. Y.: Variations of tunneling properties in poly(lactic acid) (PLA)/poly (ethylene oxide) (PEO)/carbon nanotubes (CNT) nanocomposites during hydrolytic degradation. Sensors and Actuators A: Physical, 274, 28-36 (2018).

https://doi.org/10.1016/j.sna.2018.03.004

[32] da Silva A. P., do Amaral Montanheiro T. L., Montagna L. S., Andrade P. F., Durán N., Lemes A. P.: Effect of carbon nanotubes on the biodegradability of poly(3-hydroxybutyrate-co-3-hydroxyvalerate) nanocomposites. Journal of Applied Polymer Science, 136, 48020/148020/10 (2019).

https://doi.org/10.1002/app.48020

[33] Montagna L. S., Oyama I. C., Lamparelli R. C. B. C., Silva A. P., do Amaral Montanheiro T. L. A., Lemes A. P.: Evaluation of biodegradation in aqueous medium of poly(hydroxybutyrate-co-hydroxyvalerate)/carbon nanotubes films in respirometric system. Journal Renewable Materials, 7, 117-128 (2019).

https://doi.org/10.32604/jrm.2019.00036

[34] Kuan C-F., Kuan H-C., Ma C-C. M., Chen C-H.: Mechanical and electrical properties of multi-wall carbon nanotube/poly(lactic acid) composites. Journal of Physics and Chemistry of Solids, 69, 1395-1398 (2008).

https://doi.org/10.1016/j.jpcs.2007.10.060

[35] Lizundia E., Sarasua J. R., D’Angelo F., Orlacchio A., Martino S., Kenny J. M., Armentano I.: Biocompatible poly(L-lactide)/MWCNT nanocomposites: Morphological characterization, electrical properties, and stem cell interaction. Macromolecular Bioscience, 12, 870-881 (2012).

https://doi.org/10.1002/mabi.201200008
[36] Mina M. F., Beg M. D. H., Islam M. R., Alam A. K. M. M., Nizam A., Younus R. M.: Characterization of biodegradable nanocomposites with poly(lactic acid) and multi-walled carbon nanotubes. International Journal of Materials and Metallurgical Engineering, 1, 74-79 (2013).

https://doi.org/10.5281/zenodo.1081613

[37] Quan H., Zhang S-J., Qiao J-L., Zhang L-Y.: The electrical properties and crystallization of stereocomplex poly(lactic acid) filled with carbon nanotubes. Polymer, 53, 4547-4552 (2012). https://doi.org/10.1016/j.polymer.2012.07.061

[38] Cui C-H., Yan D-X., Pang H., Xu X., Jia L-C., Li Z-M.: Formation of a segregated electrically conductive network structure in a low-melt-viscosity polymer for highly efficient electromagnetic interference shielding. ACS Sustainable Chemistry and Engineering, 4, $4137-$ 4145 (2016).

https://doi.org/10.1021/acssuschemeng.6b00526

[39] do Amaral Montanheiro T. L., Cristóvan F. H., Machado J. P. B., Tada D. B., Durán N., Lemes A. P.: Effect of MWCNT functionalization on thermal and electrical properties of PHBV/MWCNT nanocomposites. Journal of Materials Research, 30, 55-65 (2014).

https://doi.org/10.1557/jmr.2014.303

[40] Lemes A. P., do Amaral Montanheiro T. L. A., Passador F. R., Durán N.: Nanocomposites of polyhydroxyalkanoates reinforced with carbon nanotubes: Chemical and biological properties. in 'Eco-friendly polymer nanocomposites' (eds.: Thakur V., Thakur M.) Springer, New Delhi, 79-108 (2015). https://doi.org/10.1007/978-81-322-2470-9 3

[41] Kim P., Shi L., Majumdar A., McEuen P. L.: Thermal transport measurements of individual multiwalled nanotubes. Physical Review Letters, 87, 215502/1-215502/4 (2001).

https://doi.org/10.1103/PhysRevLett.87.215502

[42] Wang Y., Weng G. J.: Electrical conductivity of carbon nanotube- and graphene-based nanocomposites. in 'Micromechanics and nanomechanics of composite solids' (eds.: Meguid S. A., Weng G. J.) Springer International Publishing, 123-156 (2018).

https://doi.org/10.1007/978-3-319-52794-9_4

[43] Treacy M. M. J., Ebbesen T. W., Gibson J. M.: Exceptionally high Young's modulus observed for individual carbon nanotubes. Nature, 381, 678-680 (1996). https://doi.org/10.1038/381678a0

[44] Yu M-F., Files B. S., Arepalli S., Ruoff R. S.: Tensile loading of ropes of single wall carbon nanotubes and their mechanical properties. Physical Review Letters, 84, 5552-5555 (2000). https://doi.org/10.1103/PhysRevLett.84.5552

[45] Qiu H., Yang J.: Structure and properties of carbon nanotubes. in 'Industrial applications of carbon nanotubes' (eds.: Peng H., Li Q., Chen T.) Elsevier, Amsterdam, 47-69 (2016). https://doi.org/10.1016/B978-0-323-41481-4.00002-2 
[46] Zaporotskova I. V., Boroznina N. P., Parkhomenko Y. N., Kozhitov L. V.: Carbon nanotubes: Sensor properties. A review. Modern Electronic Materials, 2, 95-105 (2016). https://doi.org/10.1016/j.moem.2017.02.002

[47] Razavi R., Zare Y., Rhee K. Y.: A model for tensile strength of polymer/carbon nanotubes nanocomposites assuming the percolation of interphase regions. Colloids Surfaces A: Physicochemical an Engineering Aspects, 538, 148-154 (2018).

https://doi.org/10.1016/j.colsurfa.2017.10.063

[48] Zare Y., Rhim S., Garmabi H., Rhee K. Y.: A simple model for constant storage modulus of poly(lactic acid)/poly(ethylene oxide)/carbon nanotubes nanocomposites at low frequencies assuming the properties of interphase regions and networks. Journal of the Mechanical Behavior of Biomedical Materials, 80, 164 170 (2018).

https://doi.org/10.1016/j.jmbbm.2018.01.037

[49] Braga N. F., LaChance A. M., Liu B., Sun L., Passador F. R.: Influence of compatibilizer and carbon nanotubes on mechanical, electrical, and barrier properties of PTT/ ABS blends. Advanced Industrial and Engineering Polymer Research, 2, 121-125 (2019). https://doi.org/10.1016/j.aiepr.2019.07.002

[50] Braga N. F., Zaggo H. M., Montagna L. S., Passador F. R.: Effect of carbon nanotubes (CNT) functionalization and maleic anhydride-grafted poly(trimethylene terephthalate) (PTT-g-MA) on the preparation of antistatic packages of PTT/CNT nanocomposites. Jounal of Composites Science, 4, 44/1-44/18 (2020).

https://doi.org/10.3390/jcs4020044

[51] Braga N. F., Ding H., Sun L., Passador F. R.: Antistatic packaging based on PTT/PTT-g-MA/ABS/MWCNT nanocomposites: Effect of the chemical functionalization of MWCNTs. Journal of Applied Polymer Science, 138, 50005/1-50005/11 (2021). https://doi.org/10.1002/app.50005

[52] Jiang D., Murugadoss V., Wang Y., Lin J., Ding T., Wang Z., Shao Q., Wang C., Liu H., Lu N., Wei R., Subramania A., Guo Z.: Electromagnetic interference shielding polymers and nanocomposites - A review. Polymer Reviews, 59, 280-337 (2019). https://doi.org/10.1080/15583724.2018.1546737

[53] Geetha S., Kumar K. K. S., Rao C. R. K., Vijayan M., Trivedi D. C.: EMI shielding: Methods and materials A review. Journal of Applied Polymer Science, 112, 2073-2086 (2009). https://doi.org/10.1002/app.29812

[54] Thomassin J-M., Jérôme C., Pardoen T., Bailly C., Huynen I., Detrembleur C.: Polymer/carbon based composites as electromagnetic interference (EMI) shielding materials. Materials Science and Engineering R, 74, 211-232 (2013).

https://doi.org/10.1016/j.mser.2013.06.001
[55] Zare Y., Rhee K. Y., Park S-J.: Modeling the roles of carbon nanotubes and interphase dimensions in the conductivity of nanocomposites. Results in Physical, 15, 102562/1-102562/8 (2019). https://doi.org/10.1016/j.rinp.2019.102562

[56] Wu D., Zhang Y., Zhang M., Yu W.: Selective localization of multiwalled carbon nanotubes in poly( $\varepsilon$-caprolactone)/polylactide blend. Biomacromolecules, 10, 417424 (2009). https://doi.org/10.1021/bm801183f

[57] Wu D., Lin D., Zhang J., Zhou W., Zhang M., Zhang Y., Wang D., Lin B.: Selective localization of nanofillers: Effect on morphology and crystallization of PLA/PCL blends. Macromolecular Chemistry and Physics, 212, 613-626 (2011). https://doi.org/10.1002/macp.201000579

[58] Wu S.: Polymer interface and adhesion. New York (1982).

[59] Owens D. K., Wendt R. C.: Estimation of the surface free energy of polymers. Journal of Applied Polymer Science, 13, 1741-1747 (1969). https://doi.org/10.1002/app.1969.070130815

[60] Dalal E. N.: Calculation of solid surface tensions. Langmuir, 3, 1009-1015 (1987). https://doi.org/10.1021/la00078a023

[61] Nuriel S., Liu L., Barber A. H., Wagner H. D.: Direct measurement of multiwall nanotube surface tension. Chemical Physics Letters, 404, 263-266 (2005). https://doi.org/10.1016/j.cplett.2005.01.072

[62] Barber A. H., Cohen S. R., Wagner H. D.: Static and dynamic wetting measurements of single carbon nanotubes. Physical Review Letters, 92, 186103/1-186103/4 (2004). https://doi.org/10.1103/PhysRevLett.92.186103

[63] Sumita M., Sakata K., Asai S., Miyasaka K., Nakagawa H.: Dispersion of fillers and the electrical conductivity of polymer blends filled with carbon black. Polymer Bulletin, 25, 265-271 (1991). https://doi.org/10.1007/BF00310802

[64] ASTM D256-10: Standard test methods for determining the Izod pendulum impact resistance of plastics (2015). https://doi.org/10.1520/D0256-10

[65] ASTM D790-10: Standard test methods for flexural properties of unreinforced and reinforced plastics and electrical insulating materials (2010). https://doi.org/10.1520/D0790-10

[66] Arroyo J., Ryan C.: Incorporation of carbon nanofillers tunes mechanical and electrical percolation in PHBV: PLA blends. Polymers, 10, 1371/1-1371/22 (2018). https://doi.org/10.3390/polym10121371

[67] Xiu H., Bai H. W., Huang C. M., Xu C. L., Li X. Y., Fu Q.: Selective localization of titanium dioxide nanoparticles at the interface and its effect on the impact toughness of poly(L-lactide)/poly(ether) urethane blends. Express Polymer Letters, 7, 261-271 (2013). https://doi.org/10.3144/expresspolymlett.2013.24 
[68] Nampoothiri K. M., Nair N. R., John R. P.: An overview of the recent developments in polylactide (PLA) research. Bioresource Technology, 101, 8493-8501 (2010). https://doi.org/10.1016/j.biortech.2010.05.092

[69] Aoyagi Y., Yamashita K., Doi Y.: Thermal degradation of poly[(R)-3-hydroxybutyrate], poly[ $\varepsilon$-caprolactone], and poly[(S)-lactide]. Polymer Degradation an Stability, 76, 53-59 (2002).

https://doi.org/10.1016/S0141-3910(01)00265-8

[70] Carli L. N., Crespo J. S., Mauler R. S.: PHBV nanocomposites based on organomodified montmorillonite and halloysite: The effect of clay type on the morphology and thermal and mechanical properties. Composites Part A: Applied Science and Manufacturing, 42, 1601-1608 (2011).

https://doi.org/10.1016/j.compositesa.2011.07.007
[71] do Amaral Montanheiro T. L., Campos T. M. B., Montagna L. S., da Silva A. P., Ribas R. G., de Menezes B. R. C., Passador F. R., Thim G. P.: Influence of CNT pre-dispersion into $\mathrm{PHBV} / \mathrm{CNT}$ nanocomposites and evaluation of morphological, mechanical and crystallographic features. Materials Research Express, 6, 105375/1-105375/9 (2019). https://doi.org/10.1088/2053-1591/ab42ed

[72] Faez R., Rezende M. C., Martin I. M., de Paoli M-A.: Intrinsically conducting polymers and their potencial in electromagnetic interference shielding (in Portugese). Polímeros, 10, 130-137 (2000). https://doi.org/10.1590/S0104-14282000000300009

[73] Lee S. M.: International encyclopedia of composites. Wiley-VCH, New York (1991).

[74] Moradi M., Naghdi N., Hemmati H., Asadi-Samani M., Bahmani M.: Effect of ultra high frequency mobile phone radiation on human health. Electronic Physician, 8, 2452-2457 (2016).

https://doi.org/10.19082/2542 